\title{
Giovanni Bottiroli, «Non si racconta impunemente una storia di castrazione». Il contagio delle identità in "Sarrasine"
}

\section{Marco Stupazzoni}

\section{(2) OpenEdition \\ 1 Journals}

\section{Edizione digitale}

URL: http://journals.openedition.org/studifrancesi/4402

DOI: $10.4000 /$ studifrancesi.4402

ISSN: 2421-5856

\section{Editore}

Rosenberg \& Sellier

\section{Edizione cartacea}

Data di pubblicazione: 1 settembre 2016

Paginazione: 344

ISSN: 0039-2944

\section{Notizia bibliografica digitale}

Marco Stupazzoni, « Giovanni Bottiroli, «Non si racconta impunemente una storia di castrazione». II contagio delle identità in "Sarrasine" », Studi Francesi [Online], 179 (LX | II) | 2016, online dal 01 septembre 2016, consultato il 18 septembre 2020. URL : http://journals.openedition.org/studifrancesi/4402 ; DOI : https://doi.org/10.4000/studifrancesi.4402

\section{Questo documento è stato generato automaticamente il 18 settembre 2020.}

\section{cc) (†) $\odot$}

Studi Francesi è distribuita con Licenza Creative Commons Attribuzione - Non commerciale - Non opere derivate 4.0 Internazionale. 


\title{
Giovanni Bottiroli, «Non si racconta impunemente una storia di castrazione». Il contagio delle identità in "Sarrasine"
}

\author{
Marco Stupazzoni
}

\section{NOTIZIA}

GIOVANNI BOTTIROLI, «Non si racconta impunemente una storia di castrazione». Il contagio delle identità in "Sarrasine", in Le Lettere e le Arti, due giornate in memoria di Daniela De Agostini, a cura di Margareth Amatulli e Anna Bucarelli, Frankfurt am Main, Peter Lang Edition, 2015, «Peregre. Nuova Serie», pp. 51-64.

1 Sarrasine è la storia di una passione penetrata da un legame di identificazione che conduce ad esiti estremi: la minuziosa lettura analitica del racconto balzachiano operata da Roland Barthes nel 1970 incarna un ben preciso modello di critica a cui Bottiroli fa riferimento per mettere in luce alcuni limiti della interpretazione barthesiana e per liberare «le migliori intuizioni di $S / Z$ da un'impalcatura teorica per taluni versi insufficiente o superata» (p. 51). Il carattere enigmatico del testo di Balzac si nutre di uno stile di pensiero che l'A. definisce "antiseparativo», vale a dire fondato su un concetto di verità la cui espressione scaturisce dal legame tra gli opposti. È, in modo particolare, la scelta operata dall'A. di indagare sui meccanismi della trama e della messa in scena del desiderio che consente di determinare, anche in base agli esiti più suggestivi delle teorie lacaniane, un'analisi più peculiare del rapporto tra identità $\mathrm{e}$ desiderio e di determinare una nuova linea di lettura per questo racconto.

Nell'opera in questione, Balzac esprime una visione relazionale dell'identità: attraverso l'esperienza di «antisublimazione» vissuta dallo scultore Sarrasine, si fa strada, nel racconto, la «confusione tra bellezza fisica e bellezza artistica» (p. 59). Egli subisce il 
trauma della vera identità di Zambinella proprio perché non potrà mai innamorarsi dell'imperfezione: anche Zambinella è "un velo che non può essere sollevato» e le seduzioni che incantano Sarrasine «non sono cancellabili dalla coperta della sua vera identità, la castratura» (p. 62). In altri termini, la volontà distruttrice di Sarrasine deriva dall'impossibilità di rinunciare al contagio dell'identificazione. 